\title{
A comparison of alcohol measures as predictors of psychological distress in the New Zealand population
}

\author{
James Foulds ${ }^{1}$, J. Elisabeth Wells ${ }^{2}$, Cameron Lacey ${ }^{1}$, Simon Adamson ${ }^{3}$, J. Douglas Sellman ${ }^{3}$, and Roger \\ Mulder ${ }^{1}$ \\ ${ }^{1}$ Department of Psychological Medicine, University of Otago, Christchurch, New Zealand \\ ${ }^{2}$ Department of Public Health and General Practice, University of Otago, Christchurch, New Zealand \\ ${ }^{3}$ National Addiction Centre, Department of Psychological Medicine, University of Otago, Christchurch, New Zealand
}

\begin{abstract}
Aims: To compare measures of alcohol consumption and alcohol problems as predictors of current psychological distress.

Design: Logistic regression models investigated the association between alcohol measures and high psychological distress overall and separately for women and men.

Setting: Cross-sectional data from a New Zealand household population sample.

Participants: 12,488 participants aged 15 and over.

Measures: The Alcohol Use Disorders Identification Test (AUDIT) and its component factors representing consumption (AUDIT-C) and alcohol problems (the remaining items). High psychological distress was defined as a K10 score of 12 or more.

Findings: The overall prevalence of high distress was 6.5\%. High distress was present in $10.1 \%$ of abstainers, $3.4 \%$ of moderate drinkers and $35.1 \%$ of those with AUDIT scores $20+$. There was some evidence for gender differences in the association between drinking and mental health, but a relative excess of distress among male abstainers mainly accounted for this. Gender differences were less clear for heavy drinkers. Substantially elevated levels of high distress were only apparent in a small group of people with very high consumption levels (AUDIT-C $\geq 10$ ) or multiple problems. Alcohol problems appeared to be slightly better than consumption as a predictor of high distress.
\end{abstract}

Conclusions: Firstly, there is some evidence that the association between alcohol use and psychological distress varies according to gender. Secondly, although alcohol use is clearly associated with poor mental health, an excess of mental health problems is largely confined to male abstainers and a relatively small group with very heavy consumption or multiple alcohol problems.

Alcohol and common mental illnesses make major contributions to the global burden of disease (Lopez, Mathers, Ezzati, Jamison, \& Murray, 2006). A strong association between alcohol disorders and mental disorders has been consistently found in population surveys in New Zealand and elsewhere (Grant et al., 2004; Kessler, Chiu, Demler, \& Walters, 2005; Scott, McGee, Oakley Browne, \& Wells, 2006; Teesson, 2000). Studies also show a Jshaped relationship between alcohol consumption and mental illness, with both abstainers and heavy drinkers at greater risk than moderate drinkers (Alati et al., 2005; Caldwell et al., 2002; Lucas, Windsor, Caldwell, \&
Rodgers, 2010; Power, 1998; Rodgers et al., 2000; Rodgers, Parslow, \& Degenhardt, 2007; Skogen, Harvey, Henderson, Stordal, \& Mykletun, 2009; Tsai, Floyd, O'Connor, \& Velasquez, 2009).

Most of the studies examining alcohol-related mental health comorbidity used measures of total alcohol consumption or focus only on the presence or absence of an alcohol-use disorder, and few studies included comprehensive measures of alcohol problems. Those studies that examined specific aspects of drinking in relation to mental health suggest that heavy episodic drinking is a better predictor than total

Corresponding Author: James Foulds, Department of Psychological Medicine, University of Otago, Christchurch, PO Box 4345, Christchurch 8140, New Zealand. Telephone: +64-3-3720-400, Fax: +64-3-3720-407, Email: james.foulds@otago.ac.nz

Sources of financial support: The New Zealand Health Survey 2006/07 was funded by the New Zealand Ministry of Health. The New Zealand Crown is the owner of the copyright of the data. The results presented in this paper are the work of the authors, and the authors take full responsibility for the research outputs. The authors were employed by the University of Otago, New Zealand, and received no external funding to conduct this work.

Keywords: Alcohol Use Disorders Identification Test, alcohol-related disorders, comorbidity, psychological stress, sex factors 
consumption, particularly for depressive symptoms (Graham et al., 2011; Graham, Massak, Demers, \& Rehm, 2007; Graham \& Schmidt, 1999; Manninen, Poikolainen, Vartiainen, \& Laatikainen, 2006; Paljärvi et al., 2009; Patten, 1998; Wang \& Patten, 2002). Gender may also influence this association, with a stronger association previously found for females, though this may vary according to how mental illness is measured (Graham et al., 2007). Cross-cultural differences in the relationship between distress and drinking have also been recently reported (Wilsnack, Kristjanson, Wilsnack, \& Benson, 2012).

The Alcohol Use Disorders Identification Test (AUDIT) is a well-validated and widely used 10-item scale designed to detect harmful or hazardous drinking in the past 12 months (Saunders, Aasland, Babor, De La Fuente, \& Grant, 1993). The AUDIT was developed with three domains, measuring consumption, dependence features and drinking consequences (Babor, Higgins-Biddle, Saunders, \& Monteiro, 2001), though a two-domain solution has been suggested, with the first three items (also known as the AUDIT-C) representing consumption and the remaining seven representing alcohol problems or consequences (Maisto, Conigliaro, McNeil, Kraemer, \& Kelley, 2000; Peng, Wilsnack, Kristjanson, Benson, \& Wilsnack, 2012; Smith, Shevlin, Murphy, \& Houston, 2010). These properties suggest the AUDIT may be a useful tool to determine how different aspects of alcohol use relate to other outcomes.

The mental health comorbidity associated with alcohol use has commonly been measured using either structured interviews to diagnose specific disorders (for example, major depressive disorder) or dimensional scales that measure some specific aspect of mental health. In this study, mental health status was determined according to the presence of high psychological distress using the K10 scale (Kessler et al., 2002).

\section{Aims of the Study}

The first aim of this study was to measure, using the full AUDIT, the relationship between hazardous alcohol use and psychological distress in the New Zealand population, including estimation of any interaction between gender and alcohol use. The second aim of the study was to separate the AUDIT into its previously described component factors representing consumption and alcohol problems, and to determine the relative strength of each factor as a predictor of current psychological distress.

\section{METHOD}

The 2006/07 New Zealand Health Survey involved face-toface interviews with 12,488 participants aged 15 and over residing in permanent private dwellings. Participation was voluntary. The sample was obtained using clustered sampling methods with oversampling for Māori (the indigenous people), Pacific and Asian people. The sampling procedures have previously been described in detail (Ministry of Health, 2008). The survey had a weighted response rate of $67.9 \% ; 5,273$ men and 7,215 women participated. The sample included 3,160 Māori, 1,033 Pacific, 1,513 Asian and 8,593 people of European or other ethnicity, with some people identifying with more than one ethnic group. People aged 15 to 24 and men aged 25 to 64 were less likely to participate.

\section{Measures}

AUDIT: The AUDIT was administered to past-year drinkers. Its 10 items are scored 0-4. Total scores can range from 0-40. The three consumption questions in the AUDIT measure frequency of drinking, frequency of six or more standard drinks (10 grams of alcohol) per occasion, and usual number of standard drinks per occasion.

The AUDIT was analyzed using nine categories $(0 ; 1 ; 2-3$; $4-5 ; 6-7 ; 8-9 ; 10-14 ; 15-19 ; 20-40)$. Cut-points were selected in order to identify abstainers (AUDIT $=0$ ), lowrisk drinkers (AUDIT 1-7) hazardous drinkers (AUDIT $\geq$ 8 ) and those likely to have severe problems (AUDIT $\geq 20$ ) (Babor et al., 2001). The additional cut-points simply allowed the shape of the curve to be defined more precisely. In addition, actual AUDIT scores were used in cubic spline models (Durrleman, 1989).

The AUDIT was also separated into the three consumption items, also known as the AUDIT-C, in five categories $(0 ; 1-$ 3 ; 4-6; 7-9; 10-12) and an alcohol problems factor comprising the other seven AUDIT items, also in five categories (abstainers; drinkers scoring 0, 1-3, 4-7 and 828). In both cases, cut-points were chosen to create clinically meaningful categories and to retain sufficient categories to indicate the shape of the curve. For example, a cut-point of 4 on the AUDIT-C was included because this cut-point is suggested to screen for hazardous drinking (Reinert \& Allen, 2007).

Analyses were also conducted using two further consumption measures derived from the AUDIT: a quantity-frequency index from the first two AUDIT questions, using the Shakeshaft method (Shakeshaft, Bowman, \& Sanson-Fisher, 1999), and a measure of heavy episodic drinking taken from the third question in the AUDIT. This item asks about frequency of consuming six or more drinks per occasion, consistent with a previous definition of heavy episodic drinking (Kypri \& Langley, 2003).

K10: The K10 is a 10-item scale measuring psychological distress in the past four weeks (Andrews, Slade, \& Issakidis, 2002; Kessler et al., 2002; Oakley Browne, Wells, Scott, \& McGee, 2010). Individual items were scored 0-4 in this survey. Therefore total scores could range from 0-40. Due to the positively skewed distribution of K10 scores, and the group of interest being specifically those participants who were at risk of serious mental illness (Oakley Browne et al., 2010), the K10 score was transformed into a binary variable, with those scoring 12 or more defined as having high distress. 


\section{Covariates}

Covariates known to be associated with alcohol use or psychological distress were chosen. Alcohol consumption (New Zealand Ministry of Health, 2009) and psychological distress (Oakley Browne et al., 2010) decline with age, show gender and ethnic differences (New Zealand Ministry of Health, 2009; Oakley Browne et al., 2010), and vary according to socioeconomic status and tobacco use (Degenhardt \& Hall, 2001). Age categories were 15-17; 18-24; 25-34; 35-44; 45-54; 55-64; 65-74; and 75 and over. Ethnic status was categorized as: Māori; Asian; Pacific; and European or Other. Socioeconomic status was measured by education, employment, neighborhood deprivation, government transfer payment receipt, and material living standard (Jensen, Spittal, \& Krishnan, 2005). Physical health was measured using three of the physical subscales from the SF-36 (Scott, Tobias, Sarfati, \& Haslett, 1999), each included five categories. Participants were categorized as current smokers, ex-smokers or those who never smoked. Living alone or with a partner was also included as a covariate.

\section{Statistical Analysis}

Data were analyzed in SUDAAN 10.0.1 (Research Triangle Institute). A set of 100 calibrated replicate weights was used for variance estimation. Weighted estimates are presented. Exploratory analyses investigated the relationship between the full AUDIT score and K10, using two and four K10 categories. Logistic regression models were then used to investigate the association between alcohol measures and high psychological distress. The alcohol measures were assigned as predictor variables, as we were interested in the mental health status of groups of drinkers, particularly in relation to implications for alcohol screening (Babor \& Higgins-Biddle, 2000). Some analyses were conducted separately for males and females due to previously noted gender differences (Graham et al., 2007).
Gender differences were further elucidated using models including gender $\mathrm{x}$ AUDIT interaction terms. AUDIT scores were also modelled through a three-knot restricted cubic spline (Durrleman, 1989) which consists of two terms, a linear one and a combination of cubic functions with linear tails. Knots were set at the $5^{\text {th }}, 50^{\text {th }}$, and $95^{\text {th }}$ centiles for AUDIT scores. A composite test of significance for the interaction of sex and AUDIT scores was also carried out on these models. The possibility of individual AUDIT and K10 items overlapping was examined by calculating bivariate correlations for each combination of item pairs between the two measures. Results from logistic regressions are presented as predicted marginals rather than odds ratios (Graubard \& Korn, 1999). Estimates are presented with $95 \%$ confidence intervals.

\section{RESULTS}

AUDIT scores ranged from 0 to 33 . Women were more likely to be abstainers, and men were more likely to have elevated scores on the AUDIT. The prevalence of hazardous drinking (AUDIT $\geq 8$ ) was 19.1\% (95\% CI: $15.3,23.7)$ among $15-17$ year olds, was highest at $42.8 \%$ (95\% CI: 38.4, 47.0) in 18-24 year olds, and declined steeply in advancing age groups. Table 1 shows the distribution of AUDIT scores for males, females and overall. K10 scores ranged from 0 to 40 . High psychological distress, defined as a score of 12 or higher, was present in $6.5 \%$ (95\% CI: 6.0, 7.2). Among women, $7.4 \%$ (95\% CI: 6.6, 8.3) had high distress while in men the figure was 5.6\% (95\% CI: 4.9, 6.5). In age- and sexadjusted models, Māori (95\% CI: 9.4\%; 8.2, 10.6) and Pacific people (95\% CI: 9.9\%; 7.6, 12.1) had a greater prevalence of high distress than New Zealand Europeans (95\% CI: 5.8\%; 5.1, 6.5), but in full models ethnicity was not a significant predictor of high distress, suggesting that other variables, including socioeconomic status and physical health, explained the ethnic differences.

\section{Table 1}

Distribution of Alcohol Use Disorders Identification Test (AUDIT) scores by gender

\begin{tabular}{|c|c|c|c|c|c|c|}
\hline \multirow[b]{3}{*}{ AUDIT score } & \multicolumn{6}{|c|}{ AUDIT score distribution } \\
\hline & \multicolumn{2}{|c|}{ Males } & \multicolumn{2}{|c|}{ Females } & \multicolumn{2}{|c|}{ Overall } \\
\hline & $\%$ & $95 \% \mathrm{CI}$ & $\%$ & $95 \% \mathrm{CI}$ & $\%$ & $95 \%$ CI \\
\hline 0 & 12.3 & $11.1,13.6$ & 20.1 & $19.0,21.3$ & 16.4 & $15.5,17.2$ \\
\hline 1 & 9.1 & $8.2,10.1$ & 18.0 & $16.8,19.2$ & 13.7 & $12.9,14.6$ \\
\hline $2-3$ & 16.9 & $15.6,18.2$ & 21.5 & $20.3,22.9$ & 19.3 & $18.4,20.2$ \\
\hline $4-5$ & 22.5 & $21.1,24.0$ & 22.1 & $20.7,23.5$ & 22.3 & $21.3,23.3$ \\
\hline $8-9$ & 9.4 & $8.4,10.4$ & 4.4 & $3.7,5.1$ & 6.8 & $6.2,7.4$ \\
\hline $10-14$ & 10.9 & $9.9,12.1$ & 4.1 & $3.5,4.7$ & 7.4 & $6.8,8.0$ \\
\hline $15-19$ & 3.7 & $3.1,4.6$ & 1.4 & $1.1,1.8$ & 2.5 & $2.2,3.0$ \\
\hline $20-40$ & 1.5 & $1.2,2.0$ & 0.5 & $0.3,0.7$ & 1.0 & $0.8,1.2$ \\
\hline
\end{tabular}


Table 2 shows the association between AUDIT score and high psychological distress in a series of statistical models, for males, females and overall. In general there was a Jshaped association between the AUDIT score and high distress, with an elevated percentage of high distress in abstainers and heavy drinkers compared to moderate drinkers. Gender differences in the relationship between AUDIT and high distress were suggested in the full model, which showed a significant association for males but not females. This finding was investigated in further models, including an AUDIT by sex interaction term and with the AUDIT score as a continuous variable with a cubic spline transformation. The test statistics and associated $p$ values for these analyses are shown at the bottom of Table 2 .

They indicate modest evidence that a sex difference exists in the relationship between AUDIT and high distress, but this may be chiefly because of a relative excess of distress in male compared to female abstainers. The detailed results from these analyses are available on request.

Table 3 shows the distribution of scores on the AUDIT consumption and problems factors for males, females, and overall. Women had lower scores than men on both factors. Only about $25 \%$ of people scored above 0 on the alcohol problems item, while $48 \%$ scored 4 or more on the consumption factor, despite a threshold of 4 being commonly suggested to screen for hazardous drinking. Table 4 shows the percentage with high distress according to alcohol consumption and alcohol problems categories, with results for abstainers not presented (see Table 2 for results in abstainers). Distress was lowest with scores of 46 on the consumption factor, and highest in those with scores $10+$. Drinkers without problems had low levels of distress, while the prevalence of distress climbed steeply with increasing problems. Findings using a total consumption measure obtained from the first two AUDIT items showed the percentage with high distress was $8.6 \%$ (95\% CI: 7.6, 9.6) in abstainers; 5.9\% (95\% CI: 5.0, 7.0) for 1-7 drinks per week; $3.4 \%$ (95\% CI: $2.7,4.3)$ for $8-14$ drinks; 5.3\% (95\% CI: 3.4, 8.2) for 15-21 drinks; $12.2 \%$ (95\% CI: 7.0, 20.1) for 22-28 drinks; $12.7 \%$ (95\% CI: 7.4, $20.9)$ for $29-42$ drinks and $21.3 \%$ (95\% CI: 13.6, 31.7) for 42 or more drinks per week. In relation to heavy episodic drinking, the unadjusted percentage with high distress was greatest $(20.6 \%, 95 \%$ CI: $6.6,10.9)$ among the very small group $(0.7 \%$ of the population) who said they had six or more drinks daily or almost daily, while the percentage in those who consumed that amount weekly $(10.1 \%$ of the population) was only $8.5 \%$ (95\% CI: $6.6,10.9)$. This figure changed minimally after adjustment for age and sex.

When consumption and alcohol problems factors were simultaneously included in a regression model with a full range of covariates, higher scores on the consumption factor did not predict high distress, while elevated scores on the alcohol problems factor remained associated with high distress, though this was only apparent at high levels of alcohol problems (denoted by a score of 8 or more on this item).
Inspection of the items in the AUDIT and the K10 did not reveal overlap in content. Correlations between individual AUDIT and K10 items were small (ranging from -0.18 to 0.11). Consequently, it does not appear that the two scales are measuring the same concept.

\section{DISCUSSION}

This New Zealand household study demonstrates a Jshaped association between the score on the Alcohol Use Disorders Identification Test (AUDIT) and high psychological distress, a marker of serious mental illness. Higher levels of distress were found in both abstainers and heavy drinkers compared to moderate drinkers. There was weak evidence that the relationship between drinking and distress differs for men and women; however, this was mainly due to a relative excess of high distress in male abstainers.

Our findings are generally consistent with previous studies in the area (Caldwell et al., 2002; Lucas et al., 2010; Rodgers, et al., 2000; Rodgers et al., 2007), all of which used more basic measures of alcohol consumption. Some previous studies suggested sex differences in the relationship between drinking and mental health, with female but not male abstainers having a level of mental health problems similar to that of light drinkers (Alati et al., 2005; Caldwell et al., 2002), and our results are also consistent with this observation. The association between alcohol and mental health may also depend on the type of mental health measure used, particularly when considering gender differences (Graham et al., 2007). The failure to demonstrate a stronger association for women in this study may therefore have been due to using a non-specific measure (the K10) rather than using diagnostic criteria for a specific disorder such as depression.

In this study, the previously described factor structure of the AUDIT was used to compare alcohol consumption and alcohol-related problems as predictors of psychological distress. On both factors, elevated levels of high distress were largely confined to a small group (2-3\%) with the highest consumption or most alcohol problems. There was some indication that higher scores on the alcohol problems items were a better predictor of high distress than was the consumption score. However, due to their differing distributions and the somewhat arbitrary cut-points, this needs to be interpreted cautiously.

Heavy episodic drinking appears to be more strongly associated with mental health problems than other drinking patterns (Graham et al., 2007; Graham \& Schmidt, 1999; Manninen et al., 2006; Paljärviet al., 2009; Patten, 1998; Wang \& Patten, 2002; Wilsnack et al., 2012). Although we found a large excess of distress among the most frequent heavy episodic drinkers, this group was less than $1 \%$ of the population, and there was relatively little excess of distress in other groups of heavy episodic drinkers. This finding suggests that the heavy episodic drinking item in the 
Table 2

Percentage with high psychological distress $(K 10 \geq 12)$ by Alcohol Use Disorders Identification Test (AUDIT) score

\begin{tabular}{|c|c|c|c|c|c|c|}
\hline \multirow[b]{3}{*}{ AUDIT } & \multicolumn{6}{|c|}{ Percentage with high psychological distress $^{\mathrm{a}} \quad \%(95 \% \mathrm{CI})$} \\
\hline & \multicolumn{3}{|c|}{ Unadjusted } & \multicolumn{3}{|c|}{ Adjusted for age and ethnicity } \\
\hline & Males & Females & Overall $^{\mathrm{C}}$ & Males & Females & Overall $^{\mathrm{c}}$ \\
\hline 0 & $10.4(7.9,13.5)$ & $10.0(6.6,8.3)$ & $10.1(8.8,11.7)$ & $10.2(7.3,13.1)$ & $9.3(7.3,11.2)$ & $9.3(7.7,10.8)$ \\
\hline 1 & $5.1(2.9,8.3)$ & $7.3(5.8,9.2)$ & $6.6(5.4,8.2)$ & $5.3(2.6,6.2)$ & $7.8(6.0,9.6)$ & $6.6(5.1,8.0)$ \\
\hline $2-3$ & $4.3(2.8,6.4)$ & $5.4(4.1,7.2)$ & $4.9(3.9,6.3)$ & $4.4(2.6,6.2)$ & $5.9(4.2,7.7)$ & $5.2(3.9,6.4)$ \\
\hline $4-5$ & $2.5(1.7,3.8)$ & $4.3(3.1,6.0)$ & $3.4(2.7,4.5)$ & $2.6(1.6,3.6)$ & $4.7(3.2,6.2)$ & $3.7(2.7,4.6)$ \\
\hline $6-7$ & $3.3(2.0,5.0)$ & $7.1(4.8,10.2)$ & $4.8(3.6,6.2)$ & $3.3(1.6,3.6)$ & $6.8(4.3,9.3)$ & $5.0(3.6,6.4)$ \\
\hline $8-9$ & $4.7(2.6,7.8)$ & $8.6(5.1,14.2)$ & $6.0(4.1,8.7)$ & $4.6(2.3,7.0)$ & $7.5(3.5,11.5)$ & $6.0(3.7,8.3)$ \\
\hline $10-14$ & $7.1(4.9,10.1)$ & $12.5(8.9,17.4)$ & $8.7(6.8,11.1)$ & $6.7(4.3,9.1)$ & $9.9(6.2,13.6)$ & $8.1(6.0,10.3)$ \\
\hline $15-19$ & $11.3(6.5,17.9)$ & $21.5(13.4,32.7)$ & $14.3(10.3,19.5)$ & $10.7(5.5,15.9)$ & $16.0(8.1,23.9)$ & $13.1(8.6,17.5)$ \\
\hline $20-40$ & $32.8(20.6,48.0)$ & $41.7(22.6,62.8)$ & $35.1(24.7,47.1)$ & $29.1(16.1,42.1)$ & $31.0(12.1,49.8)$ & $30.7(19.5,42.0)$ \\
\hline $\begin{array}{l}\text { AUDIT } \\
\text { categorical }^{\mathrm{d}}\end{array}$ & $\begin{array}{r}F=10.9 \\
\mathrm{p}<0.001\end{array}$ & $\begin{array}{r}F=9.8 \\
p<0.001\end{array}$ & $\begin{array}{r}F=21.7 \\
p<0.001\end{array}$ & $\begin{array}{r}F=9.6 \\
p<0.001\end{array}$ & $\begin{array}{r}F=3.9 \\
p<0.001\end{array}$ & $\begin{array}{r}F=14.6 \\
p<0.001\end{array}$ \\
\hline $\begin{array}{l}\text { AUDIT } x \text { sex } \\
\text { interaction }^{\mathrm{e}}\end{array}$ & & & $\begin{aligned} F & =1.34 \\
p & =0.23\end{aligned}$ & & & $\begin{array}{r}F=1.2 \\
p=0.31\end{array}$ \\
\hline $\begin{array}{l}\text { AUDIT cubic } \\
\text { spline }^{f}\end{array}$ & $\begin{array}{r}F=47.7 \\
p<0.001\end{array}$ & $\begin{array}{r}F=39.6 \\
p<0.001\end{array}$ & $\begin{array}{r}F=90.3 \\
p<0.001\end{array}$ & $\begin{array}{r}F=40.8 \\
p<0.001\end{array}$ & $\begin{array}{r}F=18.8 \\
p<0.001\end{array}$ & $\begin{array}{r}F=62.3 \\
p<0.001\end{array}$ \\
\hline $\begin{array}{l}\text { Interaction and } \\
\text { cubic spline }^{\mathrm{g}}\end{array}$ & & & $\begin{array}{r}F=3.1 \\
p=0.05\end{array}$ & & & $\begin{array}{r}F=2.7 \\
p=0.07\end{array}$ \\
\hline
\end{tabular}

\begin{tabular}{|c|c|c|c|}
\hline \multirow[b]{3}{*}{ AUDIT } & \multicolumn{3}{|c|}{ Percentage with high psychological distress $^{\mathrm{a}} \quad \%(95 \% \mathrm{CI})$} \\
\hline & \multicolumn{3}{|c|}{ All covariates ${ }^{\mathbf{b}}$} \\
\hline & Males & Females & Overall $^{\mathrm{c}}$ \\
\hline 0 & $7.4(5.3,9.5)$ & $7.1(5.6,8.5)$ & $7.0(5.7,8.2)$ \\
\hline 1 & $4.9(2.5,7.3)$ & $7.6(5.8,9.4)$ & $6.4(5.1,7.8)$ \\
\hline $2-3$ & $4.4(2.7,6.1)$ & $7.2(5.4,9.0)$ & $5.9(4.5,7.2)$ \\
\hline $4-5$ & $3.7(2.2,5.1)$ & $6.0(4.2,7.8)$ & $4.8(3.6,6.1)$ \\
\hline $6-7$ & $4.0(2.4,5.6)$ & $7.6(4.8,10.3)$ & $5.7(4.2,7.2)$ \\
\hline $8-9$ & $5.2(2.9,7.6)$ & $5.5(2.6,8.3)$ & $5.6(3.5,7.6)$ \\
\hline $10-14$ & $5.8(3.7,7.9)$ & $8.0(5.0,11.1)$ & $6.8(5.1,8.5)$ \\
\hline $15-19$ & $9.3(4.9,13.6)$ & $11.0(5.8,16.1)$ & $10.0(6.8,13.3)$ \\
\hline $20-40$ & $\begin{array}{r}19.6(11.5, \\
27.7)\end{array}$ & $14.1(4.7,23.6)$ & $17.5(11.0,24)$. \\
\hline $\begin{array}{l}\text { AUDIT } \\
\text { categorical }^{\mathrm{d}}\end{array}$ & $\begin{array}{r}F=6.1 \\
p<0.001\end{array}$ & $\begin{array}{r}F=1.2 \\
p=0.31\end{array}$ & $\begin{array}{r}F=5.4 \\
p<0.001\end{array}$ \\
\hline $\begin{array}{l}\text { AUDIT x sex } \\
\text { interaction }^{\mathrm{e}}\end{array}$ & & & $\begin{array}{l}F=1.15 \\
p=0.34^{\mathrm{e}}\end{array}$ \\
\hline $\begin{array}{l}\text { AUDIT cubic } \\
\text { spline }^{\mathrm{f}}\end{array}$ & $\begin{array}{r}F=23.9 \\
p<0.001\end{array}$ & $\begin{array}{r}F=4.3 \\
p=0.02\end{array}$ & $\begin{array}{r}F=23.7 \\
p<0.001\end{array}$ \\
\hline $\begin{array}{l}\text { Interaction and } \\
\text { cubic spline }^{\mathrm{g}}\end{array}$ & & & $\begin{array}{r}F=3.2 \\
p=0.04\end{array}$ \\
\hline
\end{tabular}

\footnotetext{
${ }^{\mathrm{a}}$ Predicted marginals from logistic regression models

${ }^{\mathrm{b}}$ Model including age, ethnicity, smoking, neighbourhood deprivation, physical health, material living standard, education, employment, cohabitation, government transfer payment receipt

${ }^{\mathrm{c}}$ Model includes sex but without interaction term

${ }^{\mathrm{d}}$ Wald- $F$ for AUDIT score in 9-category models. Numerator $d f=8$

${ }^{\mathrm{e}}$ Wald- $F$ for interaction term in models with 9 category AUDIT and AUDIT X sex interaction. Numerator $d f=8$

${ }^{\mathrm{f}}$ AUDIT as a continuous variable with cubic spline. Quoted $\mathrm{p}$ value is the significance of the combined effect of the AUDIT linear and cubic components

${ }^{\mathrm{g}}$ Wald- $F$ for interaction term in models with AUDIT cubic spline and AUDIT X sex interaction. Numerator $d f=2$
} 
Table 3

Distribution of Alcohol Use Disorder Identification Test (AUDIT) scores on consumption items (AUDIT-C) and alcohol problems items

\begin{tabular}{|c|c|c|c|c|c|c|}
\hline \multirow[b]{3}{*}{ Score } & \multicolumn{6}{|c|}{ Percentage in each category } \\
\hline & \multicolumn{2}{|c|}{ Males } & \multicolumn{2}{|c|}{ Females } & \multicolumn{2}{|c|}{ Overall } \\
\hline & $\%$ & $95 \% \mathrm{CI}$ & $\%$ & $95 \% \mathrm{CI}$ & $\%$ & $95 \% \mathrm{CI}$ \\
\hline \multicolumn{7}{|c|}{ Consumption items (AUDIT-C) } \\
\hline 0 & 12.3 & $11.1,13.6$ & 20.1 & $19.0,21.3$ & 16.3 & $15.5,17.2$ \\
\hline $1-3$ & 29.2 & $27.8,30.7$ & 43.4 & $42.0,44.7$ & 36.6 & $35.5,37.6$ \\
\hline $4-6$ & 36.6 & 35.2, 38.0 & 29.4 & $28.0,30.9$ & 32.8 & $31.8,33.9$ \\
\hline $10-12$ & 3.6 & $3.0,4.3$ & 1.1 & $0.8,1.5$ & 2.3 & $2.0,2.7$ \\
\hline \multicolumn{7}{|c|}{ Alcohol problems items } \\
\hline Abstainer & 12.3 & $11.1,13.6$ & 20.1 & $19.0,21.3$ & 16.3 & $15.5,17.2$ \\
\hline $0^{\mathrm{a}}$ & 55.7 & $54.0,57.4$ & 60.5 & $59.0,62.0$ & 58.2 & $57.1,59.3$ \\
\hline $1-3$ & 17.2 & $16.1,18.4$ & 12.3 & $11.2,13.4$ & 14.7 & $13.8,15.5$ \\
\hline $4-7$ & 11.0 & $9.9,12.3$ & 5.4 & $4.8,6.1$ & 8.1 & $7.4,8.8$ \\
\hline
\end{tabular}

${ }^{\mathrm{a}}$ Score of 0 on problems items, among drinkers

AUDIT was not sufficient on its own to detect drinkers at risk of mental health problems.

Abstainers have been consistently shown to have poorer mental health than moderate drinkers (Alati et al., 2005; Lucas et al., 2010; Power, 1998; Rodgers et al., 2000).

There is still some debate about whether this finding is due to an excess of former heavy drinkers among abstainers (the "sick-quitter" effect), or other characteristics of people who choose to abstain, for example social isolation (Lucas et al., 2010). Regardless of the true explanation, the difference between abstainers and moderate drinkers generally diminishes when former heavy drinkers are excluded and potential confounding factors are accounted for (Alati et al., 2005; Lucas et al., 2010; Paschall, Freisthler, \& Lipton, 2005). Our data show this phenomenon more clearly for women than men. The poorer mental health of abstainers has attracted considerable research interest, but it remains of uncertain clinical significance in the absence of clear evidence that moderate drinking is beneficial (Beaglehole, 2009). The finding is probably more relevant in research settings, where grouping abstainers with moderate drinkers is likely to mask differences between moderate and heavy drinkers. This is particularly salient for research on specific disorders, such as alcohol dependence, in which those without the disorder are usually aggregated into a single category.

The AUDIT and its abbreviated version, the AUDIT-C, were designed as tools to screen for hazardous or harmful drinking in primary care, conditions that remain underrecognized (Foulds, Wells, Lacey, Adamson, \& Mulder, 2012). Scores of $8+$ on the AUDIT and 4 or $5+$ on the AUDIT-C suggest hazardous drinking (Reinert \& Allen, 2007). These cut-points may be reasonable if the goal is to identify drinkers at risk of long-term physical harm, but drinking that is associated with current psychological harm is mainly confined to those with an AUDIT score of $15+$ or an AUDIT-C score of 10+. The use of the alcohol problems items or the full AUDIT may give somewhat greater precision for detecting drinkers with mental illness.

\section{Limitations of the Present Study}

The main limitation of our findings is that this crosssectional study does not allow strong inferences to be made about the causal relationship between alcohol consumption, alcohol-related problems and mental health. The AUDIT also was not originally intended as a tool for answering questions about mechanisms of association between drinking and mental health conditions in the population. People in institutions were excluded from this study, but they are likely to experience high levels of both psychological distress and alcohol problems.

In summary, we have presented some further evidence that there may be gender differences in the way that alcohol use is related to mental health, with the J-shaped relationship appearing to be more robust for men. Secondly, while heavy alcohol use is associated with high psychological distress, this occurs only in a relatively small group of drinkers with the highest consumption levels or the most alcohol problems. Finally, in order to identify drinkers who are at greatest risk of mental illness, it is likely to be most useful to target those who are experiencing multiple alcohol problems, particularly as a result of consuming large quantities per occasion. 
Table 4

Percentage with high psychological distress (K10 $\geq 12)$ by Alcohol Use Disorders Identification Test Consumption (AUDIT-C) and problems scores for current drinkers ${ }^{a}$

\begin{tabular}{|c|c|c|c|c|c|c|}
\hline \multirow[b]{3}{*}{ Score } & \multicolumn{6}{|c|}{ Percentage with high psychological distress ${ }^{\mathrm{b}} \%(95 \% \mathrm{CI})$} \\
\hline & \multicolumn{3}{|c|}{ Unadjusted } & \multicolumn{3}{|c|}{ Adjusted for age and ethnicity } \\
\hline & Males & Females & Overall & Males & Females & Overall \\
\hline \multicolumn{7}{|c|}{ Consumption items (AUDIT-C) } \\
\hline $1-3$ & $5.1(3.6,6.5)$ & $6.4(5.3,7.4)$ & $5.9(5.0,6.8)$ & $5.4(3.8,6.9)$ & $6.9(5.7,8.0)$ & $6.1(5.2,7.0)$ \\
\hline $4-6$ & $3.6(2.7,4.5)$ & $6.2(4.7,7.7)$ & $4.8(4.0,5.7)$ & $3.7(2.8,4.6)$ & $6.4(4.9,7.9)$ & $5.0(4.2,5.9)$ \\
\hline $7-9$ & $5.8(4.1,7.6)$ & $9.2(6.0,12.4)$ & $6.7(5.4,8.3)$ & $5.3(3.7,7.0)$ & $7.0(4.2,9.7)$ & $6.2(4.7,7.7)$ \\
\hline $10-12$ & $14.3(8.6,20.0)$ & $24.9(12.4,37.5)$ & $17.0(12.0,23.5)$ & $12.2(7.3,17.1)$ & $17.4(7.4,27.3)$ & $14.3(9.2,19.5)$ \\
\hline Test $^{\mathrm{d}}$ & $\begin{array}{c}F=12.4 \\
p<0.001\end{array}$ & $\begin{array}{c}F=10.6 \\
p<0.001\end{array}$ & $\begin{array}{r}F=23.8 \\
p<0.001\end{array}$ & $\begin{array}{r}F=9.9 \\
p<0.001\end{array}$ & $\begin{array}{r}F=4.6 \\
p=0.002\end{array}$ & $\begin{array}{c}F=14.7 \\
p<0.001\end{array}$ \\
\hline \multicolumn{7}{|c|}{ Alcohol problems items } \\
\hline $0^{\mathrm{e}}$ & $3.3(2.4,4.3)$ & $5.4(4.6,6.2)$ & $4.5(3.9,5.1)$ & $3.4(2.4,4.4)$ & $5.9(4.9,6.8)$ & $4.7(4.0,5.4)$ \\
\hline $1-3$ & $4.8(3.3,6.4)$ & $7.8(5.5,10.0)$ & $6.1(4.9,7.6)$ & $4.9(3.3,6.5)$ & $7.1(5.0,9.2)$ & $6.0(4.7,7.3)$ \\
\hline $4-7$ & $7.7(5.3,10.2)$ & $12.4(8.3,16.5)$ & $9.4(7.5,11.6)$ & $7.4(5.0,9.8)$ & $10.7(7.0,14.3)$ & $8.9(7.0,11.0)$ \\
\hline $8-28$ & $21.2(14.7,27.7)$ & $29.9(20.0,39.8)$ & $24.1(19.0,30.1)$ & $19.6(13.5,25.7)$ & $22.5(13.5,3.1)$ & $21.4(16.0,26.8)$ \\
\hline Test $^{\mathrm{d}}$ & $\begin{array}{r}F=20.6 \\
p<0.001\end{array}$ & $\begin{array}{r}F=25.2 \\
p<0.001\end{array}$ & $\begin{array}{r}F=46.5 \\
p<0.001\end{array}$ & $\begin{array}{r}F=17.3 \\
p<0.001\end{array}$ & $\begin{array}{r}F=10.1 \\
p<0.001\end{array}$ & $\begin{array}{r}F=31.1 \\
p<0.001\end{array}$ \\
\hline
\end{tabular}

\begin{tabular}{|c|c|c|c|}
\hline \multirow[b]{3}{*}{ Score } & \multicolumn{3}{|c|}{ Percentage with high psychological distress ${ }^{\mathrm{b}} \quad \%(95 \% \mathrm{CI})$} \\
\hline & \multicolumn{3}{|c|}{ All covariates ${ }^{c}$} \\
\hline & Males & Females & Overall \\
\hline \multicolumn{4}{|c|}{ Consumption items (AUDIT-C) } \\
\hline $1-3$ & $5.1(3.7,6.5)$ & $7.3(6.1,8.5)$ & $6.3(5.4,7.2)$ \\
\hline 4-6 & $4.6(3.6,5.6)$ & $7.3(5.6,9.0)$ & $5.9(4.9,6.9)$ \\
\hline $7-9$ & $5.3(3.7,6.8)$ & $5.8(3.6,8.0)$ & $5.8(4.5,7.0)$ \\
\hline $10-12$ & $9.5(6.0,13.0)$ & $10.8(5.1,16.5)$ & $10.0(7.0,12.8)$ \\
\hline Test $^{\mathrm{d}}$ & $\begin{array}{r}F=4.5 \\
p=0.002\end{array}$ & $\begin{array}{r}F=1.1 \\
p=0.34\end{array}$ & $\begin{array}{r}F=3.9 \\
p=0.006\end{array}$ \\
\hline \multicolumn{4}{|c|}{ Alcohol problems items } \\
\hline $0^{\mathrm{e}}$ & $4.1(3.0,5.1)$ & $6.9(5.9,8.0)$ & $5.6(4.8,6.3)$ \\
\hline $1-3$ & $4.9(3.3,6.5)$ & $6.6(4.7,8.5)$ & $5.9(4.7,7.1)$ \\
\hline $4-7$ & $6.5(4.3,8.6)$ & $8.4(5.7,11.1)$ & $7.2(5.5,8.8)$ \\
\hline $8-28$ & $14.2(9.8,18.7)$ & $12.6(7.5,17.7)$ & $13.6(10.1,17.0)$ \\
\hline Test $^{d}$ & $\begin{array}{r}F=11.5 \\
p<0.001\end{array}$ & $\begin{array}{r}F=2.3 \\
p=0.07\end{array}$ & $\begin{array}{r}F=10.9 \\
p<0.001\end{array}$ \\
\hline
\end{tabular}

${ }^{a}$ See Table 2 for results for abstainers

${ }^{\mathrm{b}}$ Predicted marginals from logistic regression models

${ }^{\mathrm{C}}$ Model including age, ethnicity, smoking, neighbourhood deprivation, physical health, material living standard, education, employment, cohabitation, government transfer payment receipt

${ }^{\mathrm{d}}$ Wald- $F$ for categorical AUDIT score $(d f=4)$

${ }^{\mathrm{e}} \mathrm{S}$ core of 0 on problems items, among drinkers 


\section{REFERENCES}

Alati, R., Lawlor, D. A., Najman, J. M., Williams, G. M., Bor, W., \& O'Callaghan, M. (2005). Is there really a 'J-shaped' curve in the association between alcohol consumption and symptoms of depression and anxiety? Findings from the Mater-University Study of Pregnancy and its outcomes. Addiction, 100, 643651. doi: 10.1111/j.1360-0443.2005.01063.x

Andrews, G., Slade, T., \& Issakidis, C. (2002). Deconstructing current comorbidity: Data from the Australian National Survey of Mental Health and Well-Being. British Journal of Psychiatry, 181, 306314. doi: 10.1192/bjp.181.4.306

Babor, T. F., \& Higgins-Biddle, J. C. (2000). Alcohol screening and brief intervention: Dissemination strategies for medical practice and public health. Addiction, 95, 677-686. doi: 10.1046/j.13600443.2000.9556773.x

Babor, T. F., Higgins-Biddle, J. C., Saunders, J. B., \& Monteiro, M. G. (2001). The Alcohol Use Disorders Identification Test: Guidelines for use in primary care, 2nd edition. Geneva, Switzerland: World Health Organization.

Beaglehole, R. (2009). Alcohol: A global health priority. The Lancet, 373, 2173-2174. doi: 10.1016/s01406736(09)61168-5

Caldwell, T. M., Rodgers, B., Jorm, A. F., Christensen, H., Jacomb, P. A., Korten, A. E., \& Lynskey, M. T. (2002). Patterns of association between alcohol consumption and symptoms of depression and anxiety in young adults. Addiction, 97, 583-594. doi: 10.1046/j.1360-0443.2002.00092.x

Degenhardt, L., \& Hall, W. (2001). The relationship between tobacco use, substance-use disorders and mental health: Results from the National Survey of Mental Health and Well-being. Nicotine and Tobacco Research, 3, 225-234. doi: 10.1080/ 14622200110050457

Durrleman, S. (1989). Flexible regression models with cubic splines. Statistics in Medicine, 8, 551-561. doi: 10.1002/sim.4780080504

Foulds, J., Wells, J. E., Lacey, C., Adamson, S. J., \& Mulder, R. (2012). Harmful drinking and talking about alcohol in primary care: New Zealand population survey findings. Acta Psychiatrica Scandinavica, 126, 434-439. doi: 10.1111/j.16000447.2012.01871.x

Graham, K., Bernards, S., Knibbe, R., Kairouz, S., Kuntsche, S., Wilsnack, S. C., . . . Gmel, G. (2011). Alcohol-related negative consequences among drinkers around the world. Addiction, 106, 13911405. doi: 10.1111/j.1360-0443.2011.03425.x

Graham, K., Massak, A., Demers, A., \& Rehm, J. (2007). Does the association between alcohol consumption and depression depend on how they are measured? Alcoholism: Clinical and Experimental Research, 31, 78-88. doi: 10.1111/j.1530-0277.2006.00274.x

Graham, K., \& Schmidt, G. (1999). Alcohol use and psychosocial well-being among older adults. Journal of Studies on Alcohol, 60, 345-351.
Grant, B. F., Stinson, F. S., Dawson, D. A., Chou, S. P., Dufour, M. C., Compton, W., .. . Kaplan, K. (2004). Prevalence and co-occurrence of substance use disorders and independent mood and anxiety disorders: Results from the National Epidemiologic Survey on Alcohol and Related Conditions. Archives of General Psychiatry, 61, 807-816. doi: 10.1001/archpsyc.61.8.807

Graubard, B. I., \& Korn, E. L. (1999). Predictive margins with survey data. Biometrics, 55, 652-659. doi: 10.1111/j.0006-341X.1999.00652.x

Jensen, J., Spittal, M., \& Krishnan, V. (2005). ELSI short form: User manual for a direct measure of living standards. Wellington, New Zealand: Centre for Social Research and Evaluation.

Kessler, R., Andrews, G., Colpe, L. J., Hiripi, E., Mroczek, D. K., Normand, S. -L. T., . . . Zaslavsky, A. M. (2002). Short screening scales to monitor population prevalences and trends in non-specific psychological distress. Psychological Medicine, 32, 959-976. doi: doi:10.1017/S0033291702006074

Kessler, R., Chiu, W. T., Demler, O., \& Walters, E. E. (2005). Prevalence, severity, and comorbidity of 12month DSM-IV disorders in the National Comorbidity Survey replication. Archives of General Psychiatry, 62, 617-627. doi: 10.1001/archpsyc. 62.6.617

Kypri, K., \& Langley, J. D. (2003). Perceived social norms and their relation to university student drinking. Journal of Studies on Alcohol, 64, 829-834.

Lopez, A. D., Mathers, C. D., Ezzati, M., Jamison, D. T., \& Murray, C. J. L. (2006). Global and regional burden of disease and risk factors, 2001: Systematic analysis of population health data. The Lancet, 367, 17471757.

Lucas, N., Windsor, T. D., Caldwell, T. M., \& Rodgers, B. (2010). Psychological distress in non-drinkers: Associations with previous heavy drinking and current social relationships. Alcohol and Alcoholism, 45, 95-102. doi: 10.1093/alcalc/agp080

Maisto, S. A., Conigliaro, J., McNeil, M., Kraemer, K., \& Kelley, M. E. (2000). An empirical investigation of the factor structure of the AUDIT. Psychological Assessment, 12, 346-353.

Manninen, L., Poikolainen, K., Vartiainen, E., \& Laatikainen, T. (2006). Heavy drinking occasions and depression. Alcohol and Alcoholism, 41, 293299. doi: 10.1093/alcalc/agh246

Ministry of Health. (2008). Methodology report for the 2006/07 New Zealand Health Survey. Wellington, New Zealand: Author

Ministry of Health. (2009). Alcohol use in New Zealand: Key results of the 2007/08 New Zealand Alcohol and Drug Use Survey. Wellington, New Zealand:Author

Oakley Browne, M. A., Wells, J. E., Scott, K. M., \& McGee, M. A. (2010). The Kessler Psychological Distress Scale in Te Rau Hinengaro: The New Zealand Mental Health Survey. Australian and New Zealand Journal of Psychiatry, 44, 314-322. doi: doi:10.3109/00048670903279820 
Paljärvi, T., Koskenvuo, M., Poikolainen, K., Kauhanen, J., Sillanmäki, L., \& Mäkelä, P. (2009). Binge drinking and depressive symptoms: A 5-year population-based cohort study. Addiction, 104, 1168-1178. doi: 10.1111/j.1360-0443.2009.02577.x

Paschall, M. J., Freisthler, B., \& Lipton, R. I. (2005). Moderate alcohol use and depression in young adults: Findings from a national longitudinal study. American Journal of Public Health, 95, 453-457. doi: 10.2105/ajph.2003.030700

Patten, S. B. (1998). Alcohol consumption and major depression in the Canadian population. Canadian Journal of Psychiatry, 43, 502-506.

Peng, C. -Z., Wilsnack, R. W., Kristjanson, A. F., Benson, P., \& Wilsnack, S. C. (2012). Gender differences in the factor structure of the Alcohol Use Disorders Identification Test in multinational general population surveys. Drug and Alcohol Dependence, 124, 50-56. doi: 10.1016/j.drugalcdep.2011.12.002

Power, C. (1998). U-shaped relation for alcohol consumption and health in early adulthood and implications for mortality. The Lancet, 352, 877. doi: 10.1016/s0140-6736(98)23937-7

Reinert, D. F., \& Allen, J. P. (2007). The Alcohol Use Disorders Identification Test: An update of research findings. Alcoholism: Clinical and Experimental Research, 31, 185-199. doi: 10.1111/j.15300277.2006.00295.x

Rodgers, B., Korten, A. E., Jorm, A. F., Christensen, H., Henderson, S., \& Jacomb, P. A. (2000). Risk factors for depression and anxiety in abstainers, moderate drinkers and heavy drinkers. Addiction, 95, 18331845.

Rodgers, B., Parslow, R., \& Degenhardt, L. (2007). Affective disorders, anxiety disorders and psychological distress in non-drinkers. Journal of Affective Disorders, 99, 165-172. doi: 10.1016/j.jad. 2006.09.006

Saunders, J. B., Aasland, O. F., Babor, T. F., De La Fuente, J. R., \& Grant, M. (1993). Development of the Alcohol Use Disorders Identification Test (AUDIT): WHO collaborative project on early detection of persons with harmful alcohol consumption-II. Addiction, 88, 791-804.

Scott, K. M., McGee, M. A., Oakley Browne, M. A., \& Wells, J. E. (2006). Mental disorder comorbidity in Te Rau Hinengaro: The New Zealand Mental Health Survey. Australian and New Zealand Journal of Psychiatry, 40, 875-881. doi: 10.1111/j.14401614.2006.01906.x

Scott, K. M., Tobias, M. I., Sarfati, D., \& Haslett, S. J. (1999). SF-36 health survey reliability, validity and norms for New Zealand. Australian and New Zealand Journal of Public Health, 23, 401-406.

Shakeshaft, A. P., Bowman, J. A., \& Sanson-Fisher, R. W. (1999). A comparison of two retrospective measures of weekly alcohol consumption: Diary and quantity/frequency index Alcohol and Alcoholism, 34, 636-645. doi: 10.1093/alcalc/34.4.636

Skogen, J. C., Harvey, S. B., Henderson, M., Stordal, E., \& Mykletun, A. (2009). Anxiety and depression among abstainers and low-level alcohol consumers. The Nord-Trøndelag Health Study. Addiction, 104, 1519529. doi: 10.1111/j.1360-0443.2009.02659.x

Smith, G. W., Shevlin, M., Murphy, J., \& Houston, J. E. (2010). An assessment of the demographic and clinical correlates of the dimensions of alcohol use behaviour. Alcohol and Alcoholism, 45, 563-572. doi: 10.1093/alcalc/agq052

Teesson, M. (2000). Alcohol- and drug-use disorders in Australia: Implications of the National Survey of Mental Health and Wellbeing. Australian and New Zealand Journal of Psychiatry, 34, 206-213. doi: 10.1046/j.1440-1614.2000.00715.x

Tsai, J., Floyd, R. L., O'Connor, M. J., \& Velasquez, M. M. (2009). Alcohol use and serious psychological distress among women of childbearing age. Addictive Behaviors, 34, 146-153.

Wang, J., \& Patten, S. B. (2002). Prospective study of frequent heavy alcohol use and the risk of major depression in the Canadian general population. Depression and Anxiety, 15, 42-45. doi: 10.1002/da. 1084

Wilsnack, R. W., Kristjanson, A. F., Wilsnack, S., \& Benson, P. (2012). Distress and drinking: Crosscultural connections and contexts. International Journal of Drug and Alcohol Research, 1, 79-94. doi: 10.7895/ijadr.v1i1.37 